\title{
Engineering and process design solutions for the vertical shaft completion
}

\author{
Qiao Weiguo ${ }^{1,2}$, Pershin V.V. ${ }^{3}$, Kassikhina E.G. ${ }^{3}$, Butrim N.O. ${ }^{4}$
}

1.Shandong University of Science \& Technology, Qingdao

266510,China;2.Shandong Provincial Key Laboratory of Civil Engineering Disaster Prevention and Mitigation, Qingdao, Shandong 266510, China;3.T.F. Gorbachyov

Kuzbass State Technical University, Mining Institute, 650000, Kemerovo,

Russia;4.leading specialist, Department of capital construction and investment activities of $\mathrm{OOO}$ «UK Mechel-Mining» (LLC "Management Company

Mechel-Mining"), 125993 Moscow, Russia

\begin{abstract}
The comprehensive approach including the combination of advanced and new technical solutions with the use of modern technology opportunities providing the real possibility to reduce the vertical shaft construction labour inputs, costs and time.
\end{abstract}

Keywords: vertical shaft completion, decrease of transient periods by means of application of efficient equipment and multifunctional steel angle headgears.

\section{Introduction}

Currently the tendency to reject the construction of vertical shafts is dominated in the design of new Kuzbass mines - the preference is given to the slop mining.

This tendency is determined by some reasons:

- significant construction time of vertical shafts - $50-60 \%$ of the total duration of mine construction;

- high cost of construction of vertical shafts - 25-30\% of the total capital investment;

- lack of qualified staff due to the elimination of the most part of the specialized mine construction organizations;

- lack of engineering base in this field in Russia.

It is obvious that only a comprehensive solution of these tasks will help to select the optimal solution, which includes the study of process parameters, sinking schemes, mechanical means and equipment.

The analysis of time schedules (Fig. 1) for the construction of vertical shafts shows that at least $2 / 3$ of the total duration of the work $\mathrm{T}_{\text {общ }}$ is spent on shaft completion $\mathrm{T}_{\text {общ, equipment }} \mathrm{T}_{\text {арм }}$ and reconstruction $\mathrm{T}_{\text {переход }}$ before the operation.

$$
\mathrm{T}_{\text {переход }}=\mathrm{T}_{\text {демонтажа прох. копра }}+\mathrm{T}_{\text {монтажа }}
$$

постоянного копра



Fig. 1. Time consumption in the construction of vertical shafts

Time consumption ( $\left.\mathrm{T}_{\text {общ }}\right)$ in the construction of "Pervomayskaya" mine vertical shaft

sinking time

shaft equipment time

sinking headgear dismounting time permanent headgear mounting time completion time 
For the small-depth vertical shafts (up to $300 \mathrm{~m}$ ) the relative proportion of time spent on completion, equipment and reconstruction will be more. Therefore, a high average operation rate of sinking the extended part of the shaft does not significantly affect the shaft construction time shortening.

The real evaluation criterion of the vertical shaft construction time is the calendar rate determined taking into account the full scope of shaft construction works for the period from the beginning of its completion up to the horizontal drivage.

So, in Kuzbass, with the average operation rate of the vertical shaft sinking more than $50 \mathrm{~m} /$ month, the average calendar rate does not exceed $10 \mathrm{~m} /$ month (this rate becomes lower when the shaft depth is being decreased).

Consequently, reducing the period of shaft preparation for sinking operations is the main reserve to reduce the overall length of shaft construction in general.

For the shaft construction it is necessary to make some preparations. They are the following basic steps: surface preparation and drilling the technological part of the shaft (including the mouth); surface completion for shaft sinking, including the mounting of the headgear; shaft sinking; shaft equipment; shaft reconstruction for the construction of horizontal and slope workings, including the dismounting of the headgear for the period of sinking and permanent headgear installation.

Shaft mouth and pre-sink construction is generally regarded as an isolated construction object and equipped with the equipment other than the equipment used for the construction of an extended part of the shaft.

First, the 3-4 m depth pit for shaft mouth is excavated with an excavator on the shaft construction site. Then the permanent reinforced-concrete support for shaft mouth is erected. Also the construction of headgear foundation (sinking headgear "Sever-2" or permanent headgear) with the following pit backfilling is performed.

Further, to place the technological equipment into the shaft (sinking stage, falsework, rock-loading and drilling machines) the 35-55 $\mathrm{m}$ depth - depending on the type of equipment used and accepted technological scheme - the pre-sink is conducted. In Kuzbass conditions, the pre-sink is usually constructed in the bedrock by drilling and blasting method.

Blast-hole drilling is done manually by drills (ПП-63, ПП-54); the blasted rock is loaded with the grab KC-3 into the $1 \mathrm{~m}^{3}$ capacity bucket suspended on the crane. Concreting skip is $2.0 \mathrm{~m}$.

On the surface the rock is loaded into dump trucks with its further transportation to a waste heap.

As already mentioned, domestic mine construction organizations use hand-held drills for hole drilling during the pre-sink construction. This is due to the fact that the machine БУКС-1м (Fig. 2), which is usually used in Russia as the only equipment for drilling during the construction of vertical shafts, is applicable only after a complete pre-sink sinking.

To bring the machine into operation it is necessary to make its central string rest upon the shaft face and the loading 
machine telpher, the assembly of which in its turn is possible only after the construction of the sinking stage. Such dependence of the equipments on each other does not allow achieving high rates of sinking in the construction of pre-sink that negatively impacts on the calendar rate of shallow 200-300 m depth shaft construction, as the length of the pre-sink at such shaft depths reaches $20-25 \%$.

Currently, there is equipment for drilling for the vertical shaft sinking (Fig. 3) that can be used both for vertical shaft sinking, and for pre-sink sinking.

The proposed machine SJZ (China) does not depend on other equipment (loader, sinking stage) used shaft sinking. To be brought into operation it rests upon the bed walls. One drilling machine replaces the performance 15-18 hand-held drills.

The application of SJZ machine allows passing the pre-sink in a shorter time, and with the help of equipment that is used for further sinking of the extended part of the shaft. This reduces the transition from pre-sink construction to the construction process of the extended part of the shaft.

Thus the use of inefficient equipment is avoided and the time of transition from pre-sink construction to the construction of extended part of the shaft is reduced.

In the Russian mine construction practice the domestic analogue was used - drilling machine

СМБУ $-4 \mathrm{M}$ (KuzNIIshakhtostroy), which unfortunately is not currently produced.

The current situation has led to a significant rise in the cost of equipment (see Fig. 2, 4), required for the construction of vertical shafts, which negatively affected their already high cost. Problem can be solved in two ways: either develop domestic engineering, or find less expensive options abroad (see Fig. 3, 5). Comparable figures of to the problem solutions are shown in Table 1.

One of the possible ways of increasing the technical and economic performance of the preparatory period is maximum use during the construction of permanent buildings and utilities of the mine.

However, the experience in the construction of new mines shows that the use of permanent buildings and equipment does not exceed $50 \%$ of the design. As it can be seen from the diagram (see Fig. 1), the duration of vertical shaft completion is up to $60 \%$ of the total duration of the shaft construction also because of the interruptions in the work associated with assembly-disassembly of sinking headgear and assembly of the permanent headgear.

Noteworthy, in our opinion, is the proposal for the combination of various functions in one device during shaft sinking and exploitation.

Table 1. Comparable figures

Fig. 2 - 5УKC-1 $\mathrm{M}$
Quantity of drilling machines: 4 .
Mass: 7 t.
Drive: pneumatic.
Used in technological scheme: combined
Cost: 18,742 min. roubles (Yasinovataya
engineering plant)






\begin{tabular}{|c|c|}
\hline $\begin{array}{l}\text { (1) } \\
\text { Fig. } 4 \text { - KC- } 2 / 40\end{array}$ & 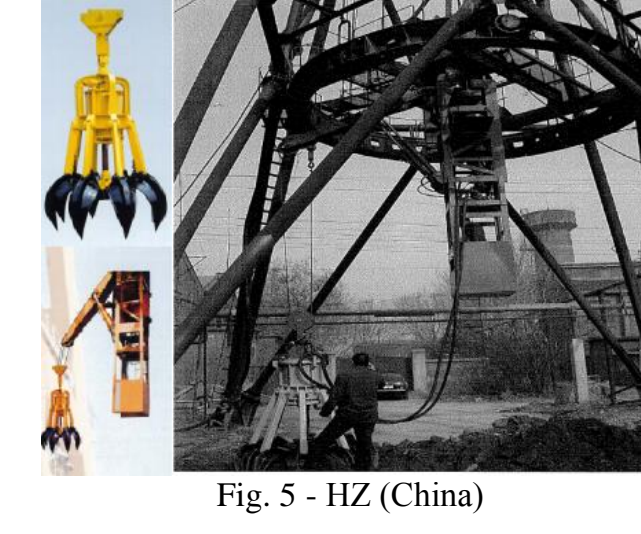 \\
\hline $\begin{array}{l}\text { Performance: } 2,3 \mathrm{~m}^{3} / \mathrm{min} \\
\text { Bucket capacity: } 1 \mathrm{~m}^{3} \\
\text { Macca: } 16 \mathrm{~T} \text {. } \\
\text { Drive: pneumatic } \\
\text { Cost: } 28,728 \text { mln. roubles } \\
\text { (Yasinovataya engineering plant) }\end{array}$ & $\begin{array}{l}\text { Performance: } 2,3 \mathrm{~m}^{3} / \mathrm{min} \\
\text { Bucket capacity: } 1 \mathrm{~m}^{3} \\
\text { Macca: } 6 \mathrm{~T} \text {. } \\
\text { Drive: hydraulic/pneumatic } \\
\text { Cost: } 5 \mathrm{mln} \text {. roubles (TS\&T CO. LTD China) }\end{array}$ \\
\hline
\end{tabular}



Fig.6.Multifunctional adgear. Model for the periodof mouth drilling



Fig.7.Multifunctionaleadge ar. Model for the periodof inking epy extended part of the shift

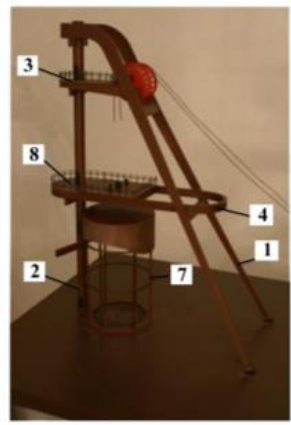

Fig.8.Multifunctionalea dgear. Model for the period of exploitation 
The department "Construction of underground structures and mines" of KuzGTU developed the steel multifunctional headgear [2], the distinguishing feature of which is the combination of fixed set of design elements in one ground device used throughout all the period of shaft construction and operation and replaceable units for its operation at sinking period (Fig. 6, 7, 8).

The idea is to develop individual headgear design [3] on the basis of the unified hardware set (box-shaped and tubular structures of variable cross section), consisting of three main functional units: the main bearing block, a temporary constructive block, additional constructive block.

The main bearing block providing the permanent lifting functions consists of under-wheel device comprising a cross brace 1 (see Fig. 6) of variable box-shaped and tubular cross section, center column 2, which can be replaced by a central tubular portal,

permanent under-wheel platforms 3 (one or two, depending on the lifting scheme), and the annular brace 4 .

It is mounted on the stage of shaft completion for the pre-sink drilling immediately after the construction of the shaft mouth and the backfill (if the headgear foundation is ready) and is used at all stages of the shaft construction and operation.

Temporary constructive block (see Fig. 7), provides the sinking functions and consists of under-wheel sinking stage 5 on the basis of the annular brace 4 and the unloading machine 6 .
It is added to under-wheel device when sinking the extended part of the shaft. Dimensions of under-wheel sinking platform allow converting it further for shaft equipping in the short term.

Additional constructive block that provides exploitation operations consists of a carrier frame machine 7 (see Fig. 8). Frame machine 7 is set to go to the construction of horizontal workings after dismounting of unloading machine 6 and the sinking under-wheel platform 5 is converted into a damper platform 8, necessary for permanent lifting.

Since the proposed headgear combines the functions of sinking and operation, such steps as the headgear dismounting for the period of sinking and the permanent headgear installation. At the same time the transition periods including the transition from the pre-sink construction to the construction of the extended part of the shaft, the transition to the equipment, as well as the transition to the construction of horizontal workings, are reduced to a minimum. Thereby the calendar rate of shaft construction is increased.

The proposed design is characterized by a reduced range of metal castings for the headgear manufacture and has 25 - 35\% smaller metal content compared to traditional solutions for similar conditions, as well as allows creating a more comfortable working environment for the maintenance of headgear equipment at the expense of lift construction inside the central tubular column.

The dimensions of the proposed headgear allow putting into the shaft the sinking stage and the bottom-hole formwork which have been already mounted on the 
surface, as well as to store and maintain the drill in it.

\section{CONCLUSIONS}

The construction of the mouth of the shaft and the pre-sink should not be regarded as the construction of the isolated objects. The equipment for the pre-sink construction should be linked to the maximum extent with technology of construction of its extended part.

The practical experience of recent years has shown that the greatest efficiency of vertical shafts construction is achieved in the case when transition periods including the transition from the pre-sink construction to the construction of the extended part of the shaft, the transition to the equipment, as well as the transition to the construction of horizontal workings, are reduced to a minimum

The proposed technical solution for the vertical shaft completion using the multifunctional headgear will develop the best way to complete the vertical shaft constructions, which allows to reduce the cost and duration of mining operations in 1.3 times, the complexity - in 1,7 times, to shorten the duration of the preparatory and transition periods in 1.2 times as compared to conventional construction methods, as well as create a more comfortable and safe environment for the headgear maintenance.

The design is protected by the Russian Federation patent. The methods of its calculation are also developed [4].

\section{REFERENCES}

[1] Baronskiy, I.V. Construction and deepening of vertical shafts / I.V. Baronskiy, V.V. Pershin, L.V. Baranov. M. : Science, 1995. -328 p.
[2] Patent № RU 2120013 C1. Steel multifunctional headgear for the construction, operation and deepening of vertical shafts / E.G. Kassikhina, V.V. Pershin.

[3] Pershin, V.V., Kassikhina, E.G. New concept of multifunctional steel headgear // Coal, 2001. - №2. - P. 11-14

[4] Kassikhina E.G. substantiation of parameters and development of the method for the multifunctional steel headgear calculation / E.G. Kassikhina, V.V. Pershin, N.F. Kosarev. - KuzSTU, 2012. - 29 p. 